\title{
纳米磁性颗粒负载的银催化剂催化苯乙烯环氧化反应
}

\author{
潘珍燕 ${ }^{1}$, 华 丽 $^{1}$, 乔云香 ${ }^{1}$, 杨汉民 ${ }^{2}$, 赵秀阁 ${ }^{1}$, 冯 博 $^{1}$, 朱闻闻 ${ }^{1}$, 侯震 山 ${ }^{1}$ \\ 1华东理工大学工业催化研究所, 结构可控先进功能材料及其制备教育部重点实验室, 上海 200237 \\ 2 中南民族大学催化材料科学湖北省重点实验室, 湖北武汉 430074
}

\begin{abstract}
摘要: 采用简单浸渍和液相还原法制备了 $\mathrm{Ag} / \mathrm{KOH}-\gamma-\mathrm{Fe}_{2} \mathrm{O}_{3}$ 催化剂, 并采用 $\mathrm{X}$ 射线衍射、透射电镜和 X射线光电子能谱等方法对 催化剂进行了表征. 结果表明, 在乙酸乙酯介质中, 以叔丁基过氧化氢为氧化剂, 该催化剂具有较高的催化苯乙烯环氧化活性, $\mathrm{KOH}$ 的添加可大幅度提高环氧化反应活性和选择性. 表征结果显示, 反应前后催化剂性质没有发生明显的变化. 另外, 所使用 的磁性载体有利于负载型银催化剂的分离和循环利用.
\end{abstract}

关键词: $\gamma$-氧化铁; 环氧化; 苯乙烯; 银; 纳米颗粒; 磁分离

中图分类号: O643 文献标识码: A

\section{Nanostructured Maghemite-Supported Silver Catalysts for Styrene Epoxidation}

\author{
PAN Zhenyan ${ }^{1}$, HUA Li ${ }^{1}$, QIAO Yunxiang ${ }^{1}$, YANG Hanmin ${ }^{2}$, ZHAO Xiuge ${ }^{1}$, FENG Bo ${ }^{1}$, \\ ZHU Wenwen ${ }^{1}$, HOU Zhenshan ${ }^{1, *}$ \\ ${ }^{1}$ Key Laboratory for Advanced Materials, Research Institute of Industrial Catalysis, \\ East China University of Science and Technology, Shanghai 200237, China \\ ${ }^{2}$ Key Laboratory of Catalysis and Materials Science of the State Ethnic Affairs Commission \& Ministry of Education, \\ Hubei Province, South-Central University for Nationalities, Wuhan 430074, Hubei, China
}

\begin{abstract}
The supported silver catalyst $\mathrm{Ag} / \mathrm{KOH}-\gamma-\mathrm{Fe}_{2} \mathrm{O}_{3}$ was prepared by simple impregnation and liquid reduction and then structurally characterized by X-ray diffraction, transmission electron microscopy, and X-ray photoelectron spectroscopy. The supported silver catalysts were highly efficient for the epoxidation of styrene using tert-butyl hydroperoxide as the oxidant and ethyl acetate as the reaction medium. The addition of $\mathrm{KOH}$ was found to increase the catalytic activity and selectivity significantly. Additionally, the magnetically recoverable $\gamma-\mathrm{Fe}_{2} \mathrm{O}_{3}$, as a support, allowed for an easy separation and recycling of the catalyst after the reaction.
\end{abstract}

Key words: $\gamma$-iron oxide; epoxidation; styrene; silver; nanoparticle; magnetic separation

The epoxidation of styrene is of considerable academic and industrial interest. Styrene oxide is a crucial and useful intermediate for fine chemicals and pharmaceuticals [1,2]. Although homogeneous catalysts always have high activity in epoxidation reactions, the conventional homogeneous catalyst systems have serious drawbacks such as catalyst recovery and product separation being very difficult $[3,4]$. Therefore, catalyst systems with high activity and strong stability are of interest. Additionally, catalysts should be able to be separated and reused easily.

Supported heterogeneous catalysts have separation and recycling advantages compared to homogenous catalysts. Various heterogeneous catalysts have been used for this reaction. Liu et al. [5] studied styrene epoxidation using the Ag- $\gamma$-ZrP catalyst with tert-butyl hydroperoxide (TBHP) as an oxidant and acetonitrile as the reaction medium, and they achieved a high yield of epoxide (89.8\%). Zhang et al. [1] reported that the $\mathrm{Ag}-\mathrm{Fe}_{3} \mathrm{O}_{4}$ nanocomposite gives high activity, selectivity and it is a magnetically separable catalyst after styrene epoxidation with TBHP as oxidant and toluene as solvent. In addition, $\mathrm{Co}-\mathrm{Y}-\mathrm{ZrO}_{2}[2], \mathrm{Ag} / \alpha-\mathrm{Al}_{2} \mathrm{O}_{3}[6]$, $\mathrm{Au} / \mathrm{CNTs}$ [7], Au-HAP [8], $\mathrm{CuO} / \mathrm{Ga}_{2} \mathrm{O}_{3}$ [9], Mn-Ti-Al-

Received 25 October 2010. Accepted 8 December 2010.

*Corresponding author. Tel: +86-21-64251686; Fax: +86-21-64253372; E-mail: houzhenshan@ecust.edu.cn

Foundation item: Supported by the National Natural Science Foundation of China (20773037, 21073058), the Research Fund for the Doctoral Program of Higher Education of China (20100074110014), and the Key Laboratory of Catalysis and Materials Science of the State Ethnic Affairs Commission and Ministry of Education, Hubei Province, South-Central University for Nationalities (CHCL10001), China.

English edition available online at ScienceDirect (http://www.sciencedirect.com/science/journal/18722067). 
MCM-41 [10], and Co/TS-1 [11] catalysts have also been reported and used for styrene epoxidation. Among the reported catalysts, the Ag-based heterogeneous catalysts are especially efficient in the epoxidation reaction.

Iron oxides are environmentally friendly and relatively cheap catalyst supports. There are many different forms of iron oxides such as $\alpha-\mathrm{Fe}_{2} \mathrm{O}_{3}, \gamma-\mathrm{Fe}_{2} \mathrm{O}_{3}, \mathrm{Fe}_{3} \mathrm{O}_{4}$, and $\mathrm{FeO}$ [12]. Generally, both $\gamma-\mathrm{Fe}_{2} \mathrm{O}_{3}$ and $\mathrm{Fe}_{3} \mathrm{O}_{4}$ have ferromagnetic properties. Nevertheless, $\gamma-\mathrm{Fe}_{2} \mathrm{O}_{3}$ as a catalyst support has many advantages. Firstly, $\gamma-\mathrm{Fe}_{2} \mathrm{O}_{3}$ is very stable during the reaction while $\mathrm{Fe}_{3} \mathrm{O}_{4}$ is gradually oxidized to $\gamma-\mathrm{Fe}_{2} \mathrm{O}_{3}$ in the presence of an oxidant $[13,14]$. Secondly, the ferromagnetic property of $\gamma-\mathrm{Fe}_{2} \mathrm{O}_{3}$ makes the isolation and recycling of the catalyst more convenient. Although pure $\gamma-\mathrm{Fe}_{2} \mathrm{O}_{3}$ often results in low catalytic activity during selective oxidations under mild reaction conditions $[3,15]$, it is very attractive as a magnetically separable catalyst support [16-18].

Although various supported catalysts have been used for styrene epoxidation, previous catalytic systems required toxic organic solvents (toluene, acetonitrile, dichloromethane, 1,2-dichloroethane, and other toxic organic solvents) and, additionally, filtration or centrifugation for the separation of the catalyst. This may result in a mechanic loss of catalyst. In addition, alkali promoters such as $\mathrm{K}_{2} \mathrm{CO}_{3}$ and $\mathrm{NaHCO}_{3}$ are always added to obtain high activity and selectivity in these oxidation reactions $[19,20]$ but these bases are difficult to reuse and they generate waste after the reaction. To eliminate these problems, a supported-base catalyst has been proposed and used accordingly [21-25]. Therefore, a clean separation and cost effective regeneration of the catalyst and purification of products can be achieved.

We used silver as a catalytically active component and then prepared a heterogeneous epoxidation catalyst by combining the advantages of a magnetic support with a supported-base promoter. In the first step, the magnetic $\gamma-\mathrm{Fe}_{2} \mathrm{O}_{3}$ nanoparticles were modified by solid base $\mathrm{KOH}$ and then silver was immobilized on the base-modified magnetic support by simple impregnation and consequent liquid reduction. Subsequently, styrene epoxidation was carried out over the prepared magnetic catalyst with low toxic ethyl acetate as the reaction solvent. We found that the as-obtained catalyst was very efficient for styrene epoxidation. Finally, the recyclability of the ferromagnetic nanocatalyst was also examined.

\section{Experimental}

\subsection{Preparation of the catalysts}

\subsubsection{Preparation of magnetic $\gamma-\mathrm{Fe}_{2} \mathrm{O}_{3}$ particles}

$\mathrm{FeCl}_{3} \cdot 6 \mathrm{H}_{2} \mathrm{O}(5.00 \mathrm{~g}, 18.5 \mathrm{mmol}$, Sinopharm Chemical
Reagent Co., Ltd., Shanghai (SCRC), AR grade) and $\left(\mathrm{NH}_{4}\right)_{2} \mathrm{SO}_{4} \cdot \mathrm{FeSO}_{4} \cdot 6 \mathrm{H}_{2} \mathrm{O}(5.44 \mathrm{~g}, 13.9 \mathrm{mmol}, \mathrm{SCRC}, \mathrm{AR}$ grade) were dissolved in $200 \mathrm{ml}$ of distilled water in a beaker. $\mathrm{NH}_{3} \cdot \mathrm{H}_{2} \mathrm{O}$ (SCRC, AR grade) was then rapidly added to the mixture under nitrogen and the $\mathrm{pH}$ of the solution was adjusted to above 9 . The whole mixture was stirred at $30{ }^{\circ} \mathrm{C}$ for a further $2 \mathrm{~h}$. The products were black precipitates. After $3 \mathrm{~h}$ of aging the black precipitates were washed with water and alcohol several times and subsequently dried at $80{ }^{\circ} \mathrm{C}$ for $6 \mathrm{~h}$ followed by calcination at $300{ }^{\circ} \mathrm{C}$ for $2 \mathrm{~h}$.

\subsubsection{Preparation of $\mathrm{KOH}-\gamma-\mathrm{Fe}_{2} \mathrm{O}_{3}$}

$\gamma-\mathrm{Fe}_{2} \mathrm{O}_{3}(2.00 \mathrm{~g})$ was impregnated with $\mathrm{KOH}(0.008 \mathrm{~g}$, $\mathrm{SCRC}, \mathrm{AR}$ grade), dissolved in $1 \mathrm{ml}$ of distilled water in a beaker and then stirred at room temperature for $24 \mathrm{~h}$. Afterwards, the mixture was dried under vacuum at $80{ }^{\circ} \mathrm{C}$ for $2 \mathrm{~h}$ followed by calcination at $300^{\circ} \mathrm{C}$ for $2 \mathrm{~h}$. Catalysts with different $\mathrm{KOH}$ loadings were also prepared.

\subsubsection{Preparation of $10 \% \mathrm{Ag} / 0.4 \% \mathrm{KOH}-\gamma-\mathrm{Fe}_{2} \mathrm{O}_{3}$}

$\mathrm{KOH}-\gamma-\mathrm{Fe}_{2} \mathrm{O}_{3}(0.200 \mathrm{~g})$, polyvinylpyrrolidone (PVP, $0.100 \mathrm{~g}, \mathrm{SCRC}, \mathrm{AR}$ grade), and $\mathrm{AgNO}_{3}(0.032 \mathrm{~g}$, (SCRC, $\mathrm{AR}$ grade) were dispersed in $1 \mathrm{ml}$ of distilled water in a beaker. The mixture was stirred at $80{ }^{\circ} \mathrm{C}$ for $8 \mathrm{~h}$ until all the silver ions in the solution were adsorbed onto the support (No residual silver ions were detected in the aqueous phase by the sodium chloride (SCRC, AR grade) test. Cooling the solution to $0{ }^{\circ} \mathrm{C}$, a $\mathrm{NaBH}_{4}(0.5 \mathrm{~mol} / \mathrm{L}, 2 \mathrm{ml}, \mathrm{SCRC}, \mathrm{AR}$ grade) aqueous solution was added to the mixture and stirred for $1 \mathrm{~h}$. The materials were then washed three times with distilled water and ethanol. The washed catalyst particles were dried under vacuum at $80{ }^{\circ} \mathrm{C}$ for $2 \mathrm{~h}$ followed by aging for $3 \mathrm{~h}$ at $80^{\circ} \mathrm{C}$ under nitrogen. The content of potassium hydroxide in the catalyst was about $0.4 \%$ as determined by ICP-AES, which confirms that the loss of potassium hydroxide was negligible during catalyst preparation. The preparation of the magnetically recoverable catalysts $\mathrm{Ag} / \mathrm{KOH}-\gamma-\mathrm{Fe}_{2} \mathrm{O}_{3}$ is shown in Scheme 1.

\subsection{Characterization of the catalysts}

The X-ray diffraction (XRD) pattern of the catalysts was analyzed by powder XRD D/max $2550 \mathrm{VB} / \mathrm{PC}$ using $\mathrm{Cu} K_{\alpha 1}$ radiation $(\lambda=0.154056 \mathrm{~nm})$. The sample was scanned over a $2 \theta$ range from $10^{\circ}$ to $80^{\circ}$ at a scanning rate of $0.02^{\circ} / \mathrm{s}$. Transmission electron microscopy (TEM) was performed with a JEOL JEM 2100T HRTEM instrument operating at $200 \mathrm{kV}$. X-ray photoelectron spectroscopy (XPS) measurements were performed on a Thermo ESCALAB $250 \mathrm{spec}-$ trometer using Nonmonochro $\mathrm{Al} K_{\alpha}$ radiation. The binding 


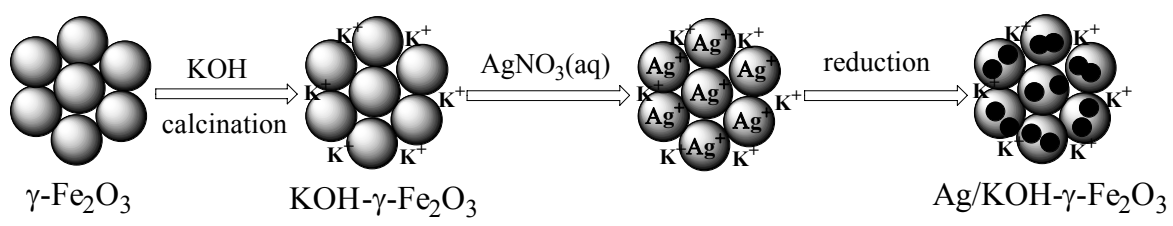

Scheme 1. Synthetic route for the magnetically recoverable catalyst $\mathrm{Ag} / \mathrm{KOH}-\gamma-\mathrm{Fe}_{2} \mathrm{O}_{3}$.

energies were calibrated with the $\mathrm{C} 1 \mathrm{~s}$ level of adventitious carbon $(284.8 \mathrm{eV})$ as the internal standard. The $\mathrm{Ag}$ and $\mathrm{K}$ contents were analyzed by ICP-AES analysis on a Varian 710-ES instrument. A Thermo Nicolet Nexus 670 was used for FT-IR characterization.

\subsection{Catalytic tests}

The catalyst $(0.020 \mathrm{~g})$, styrene $(0.104 \mathrm{~g}, 1 \mathrm{mmol}$, Shanghai Ling Feng Chemical Reagent Co., Ltd., AR grade), and ethyl acetate $(1.792 \mathrm{~g}, 2 \mathrm{ml}, \mathrm{SCRC}$, AR grade) were placed in a $25 \mathrm{ml}$ Schlenk glass flask under a $\mathrm{N}_{2}$ atmosphere and then stirred at room temperature for $30 \mathrm{~min}$. TBHP $(0.390 \mathrm{~g}$, $3 \mathrm{mmol}$, SCRC, AR grade) was added to the reaction mixture, which then proceeded for the required time at $80{ }^{\circ} \mathrm{C}$. After the reaction the catalyst was separated simply by a magnet and washed with ethyl acetate followed by drying in vacuum. The catalyst was then conveniently used for a next run. The reaction products were analyzed by gas chromatography using an FID detector.

\section{Results and discussion}

\subsection{Characterization results}

The formation of metallic $\mathrm{Ag}$ and $\gamma-\mathrm{Fe}_{2} \mathrm{O}_{3}$ in the $\mathrm{Ag} / \mathrm{KOH}-\gamma-\mathrm{Fe}_{2} \mathrm{O}_{3}$ catalyst was confirmed by powder XRD (Fig. 1). A single phase of $\gamma-\mathrm{Fe}_{2} \mathrm{O}_{3}$ was prepared successfully. The XRD pattern of the catalyst (Fig. 1(1)) shows that

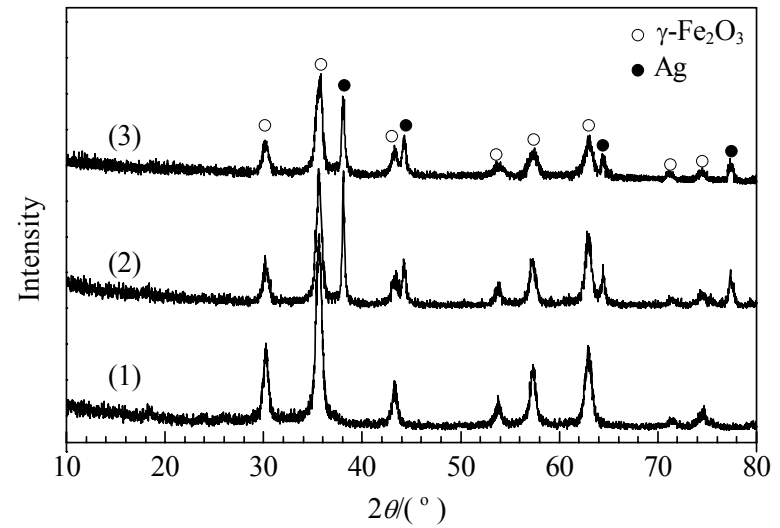

Fig. 1. $\mathrm{XRD}$ patterns of $\gamma-\mathrm{Fe}_{2} \mathrm{O}_{3}$ (1), $10 \% \mathrm{Ag} / 0.4 \% \mathrm{KOH}-\gamma-\mathrm{Fe}_{2} \mathrm{O}_{3}$ before (2) and after five runs (3). the peaks matched well with standard $\gamma-\mathrm{Fe}_{2} \mathrm{O}_{3}$ reflections (JCPDS 25-1402). Figure 1(2) shows the XRD pattern of the $10 \% \mathrm{Ag} / 0.4 \% \mathrm{KOH}-\gamma-\mathrm{Fe}_{2} \mathrm{O}_{3}$ composite. Apart from the characteristic diffraction peaks of the $\gamma-\mathrm{Fe}_{2} \mathrm{O}_{3}$ reflections the clear diffraction peaks at $2 \theta=38.12^{\circ}, 44.26^{\circ}, 64.48^{\circ}$, and $77.36^{\circ}$ are assigned to the (111), (200), (220), and (311) crystal planes of silver, respectively. These are in good agreement with the standard $\operatorname{Ag}(0)$ reflections (JCPDS 65-2871). Figure 1(3) shows the XRD pattern of the $10 \% \mathrm{Ag} / 0.4 \% \mathrm{KOH}-\gamma-\mathrm{Fe}_{2} \mathrm{O}_{3}$ composites after five runs. There was not much change in the XRD pattern compared to the fresh catalyst. The lower iron oxide diffraction was most likely due to the low crystallinity of iron oxide and the heavy atom effect arising from the silver atoms [26].

Figure 2 shows TEM photographs and the size distribution of the fresh and reused nanoparticles. The nanocomposites consisted of nearly spherical nanoparticles with an average diameter of 7-9 $\mathrm{nm}$. The overall shape and size distribution of the particles did not show obvious changes even after five runs for the magnetically separable nanocatalyst.

The surface composition and oxidation state of the nanocatalyst were also analyzed by XPS. Figure 3 shows representative XPS spectra of the nanocatalyst. Elemental analysis confirmed the presence of $\mathrm{Ag}, \mathrm{Fe}, \mathrm{K}, \mathrm{C}$, and $\mathrm{O}$. The observed XPS spectra of C $1 s(284.8 \mathrm{eV})$ and $\mathrm{O} 1 s(530.4 \mathrm{eV})$ came from adventitious carbon and iron oxides. In addition, a relatively weak Fe $3 p$ line at $56.1 \mathrm{eV}$ was also detected (Fig. 3). No other metallic signals were detected in the XPS spectra.

Figure 4 shows the Fe $2 p$ spectra of the different samples. All the Fe $2 p$ spectra show a typical iron oxide structure with broad main peaks ( $\mathrm{Fe} 2 p_{3 / 2}$ and $\mathrm{Fe} 2 p_{1 / 2}$ ). The characteristic doublet of Fe $2 p_{3 / 2}$ and $2 p_{1 / 2}$ were observed as photoelectron peaks at 710.5 and $724.1 \mathrm{eV}$, respectively. The Fe $2 p$ data were in good agreement with the values reported for $\gamma-\mathrm{Fe}_{2} \mathrm{O}_{3}$ in the literature $[27,28]$. These spectra show that the Fe $2 p$ signal intensity and binding energy of composites (1) and (2) remained unchanged. After reusing $\mathrm{Ag} / \mathrm{KOH}-$ $\gamma-\mathrm{Fe}_{2} \mathrm{O}_{3}$ five times there was also no remarkable change in the Fe $2 p$ peak intensity or the binding energy (Fig. 4(3)). These results show that the addition of $\mathrm{KOH}$ or $\mathrm{Ag}$ did not affect the structure of $\gamma-\mathrm{Fe}_{2} \mathrm{O}_{3}$ and $\gamma-\mathrm{Fe}_{2} \mathrm{O}_{3}$ was very stable during catalytic recycling. 

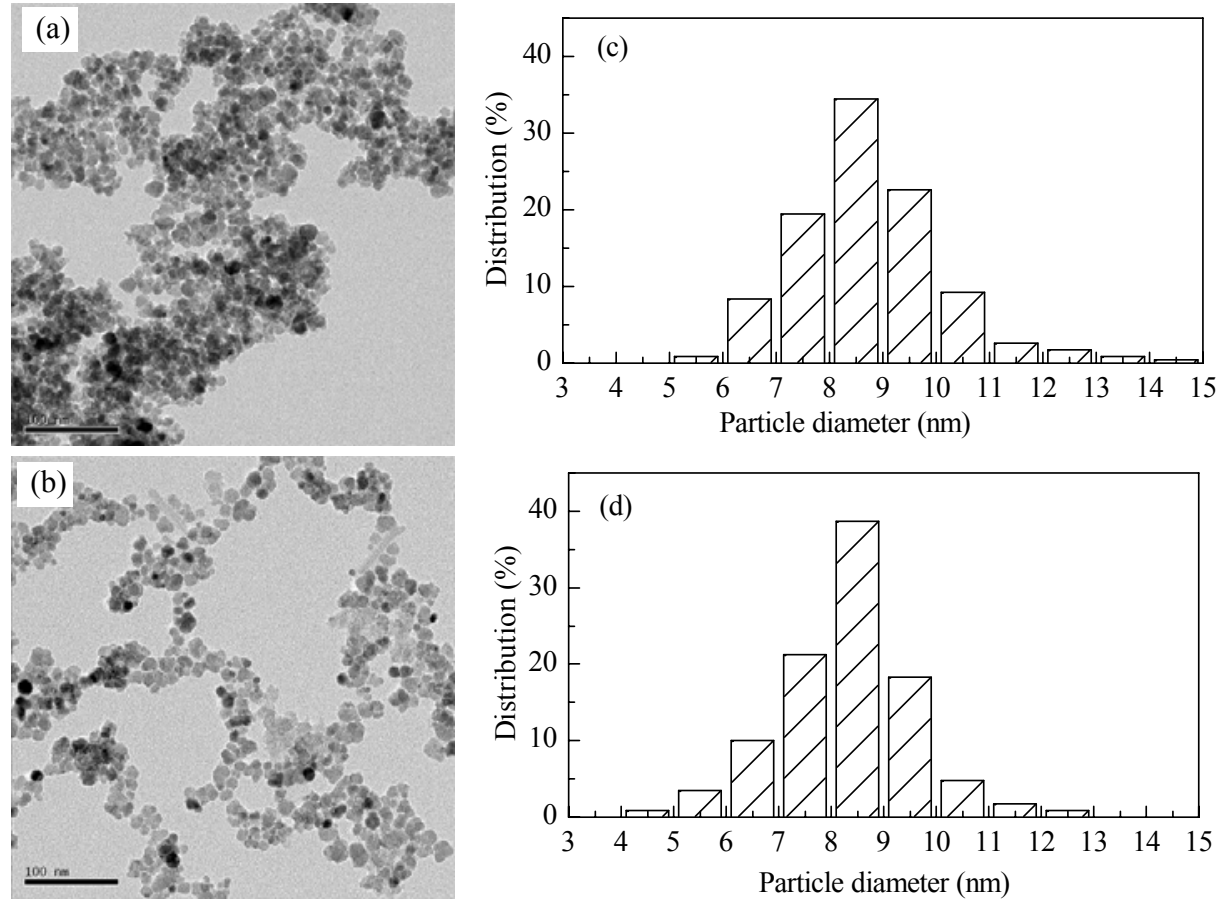

Fig. 2. TEM images ( $\mathrm{a}$ and $\mathrm{b}$ ) and particle size distribution (c and d) of $10 \% \mathrm{Ag} / 0.4 \% \mathrm{KOH}-\gamma-\mathrm{Fe}_{2} \mathrm{O}_{3}$ before (a and c) and after five runs (b and d).

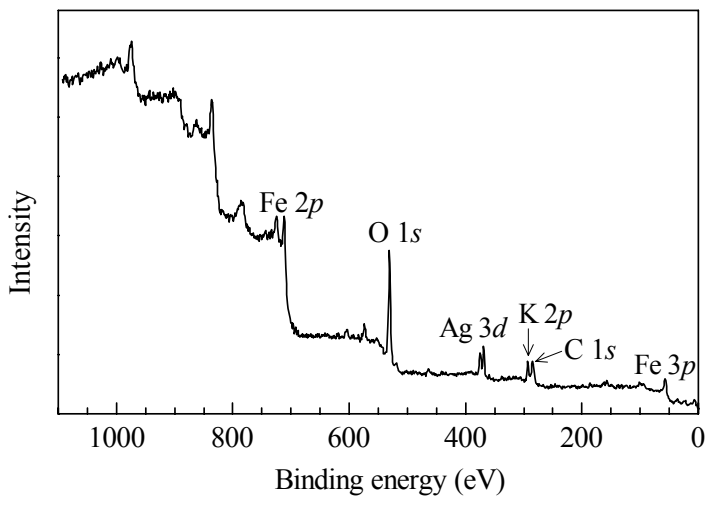

Fig. 3. The XPS spectrum of the $10 \% \mathrm{Ag} / 0.4 \% \mathrm{KOH}-\gamma-\mathrm{Fe}_{2} \mathrm{O}_{3}$ composite.

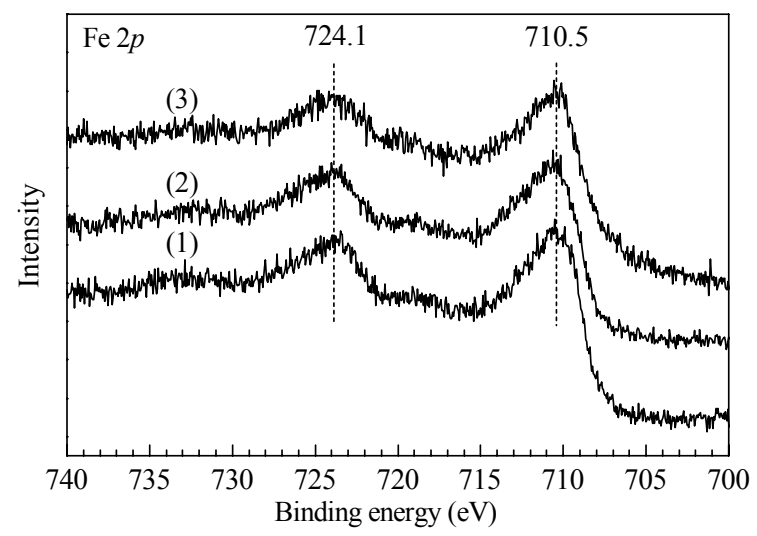

Fig. 4. Representative Fe $2 p$ XPS spectra of the composites. (1) $\mathrm{Ag} / \gamma-\mathrm{Fe}_{2} \mathrm{O}_{3}$; (2) $10 \% \mathrm{Ag} / 0.4 \% \mathrm{KOH}-\gamma-\mathrm{Fe}_{2} \mathrm{O}_{3}$; (3) $10 \% \mathrm{Ag} / 0.4 \% \mathrm{KOH}-\gamma-$ $\mathrm{Fe}_{2} \mathrm{O}_{3}$ after five runs.
To determine the oxidation state of the Ag component the XPS technique was used. Figure 5 shows the $\mathrm{Ag} 3 d$ spectra of different samples and this could be resolved into two spin orbit components, $\mathrm{Ag} 3 d_{5 / 2}$ and $\mathrm{Ag} 3 d_{3 / 2}$. Figure 5(a) gives the XPS signal of the catalyst $\mathrm{Ag}_{2} \mathrm{O} / \mathrm{KOH}-\gamma-\mathrm{Fe}_{2} \mathrm{O}_{3}$, which was not pre-reduced by $\mathrm{NaBH}_{4}$, and the main peak for $\mathrm{Ag}$ $3 d_{5 / 2}$ was present at a binding energy of $367.84 \mathrm{eV}$. This was close to the values of $\mathrm{Ag}^{+}$in $\mathrm{Ag}_{2} \mathrm{O}[29,30]$. Figure 5(b) shows the XPS spectrum of the freshly reduced $\mathrm{Ag} / \mathrm{KOH}-\boldsymbol{\gamma}-\mathrm{Fe}_{2} \mathrm{O}_{3}$ catalyst and the main peaks $\left(\mathrm{Ag} 3 d_{5 / 2}\right)$ are present at binding energies of 368.09 and $367.60 \mathrm{eV}$, respectively. This data indicates that the reduced catalyst contained a higher amount of metallic silver and less ionic silver in $\mathrm{Ag}_{2} \mathrm{O}$ [31-33]. The XRD data (Fig. 1(2)) did not indicate the presence of $\mathrm{Ag}_{2} \mathrm{O}$ but the XPS results did indicate the possible existence of a few atomic layers of $\mathrm{Ag}^{+}$ species on the nanoparticle surfaces [34]. Figure 5(c) shows the XPS spectrum of the $\mathrm{Ag} / \mathrm{KOH}-\gamma-\mathrm{Fe}_{2} \mathrm{O}_{3}$ catalyst after five runs and the main peaks $\left(\mathrm{Ag} 3 d_{5 / 2}\right)$ were present at binding energies of 368.26 and $367.79 \mathrm{eV}$. Although the XPS results show that a small amount of $\mathrm{Ag}_{2} \mathrm{O}$ was still present on the surface of the nanocatalyst the XRD data (Fig. 1(3)) showed that $\mathrm{Ag}_{2} \mathrm{O}$ was not present on the surface of the nanocatalyst. Additionally, the main peak at 368.26 $\mathrm{eV}\left(\mathrm{Ag} 3 d_{5 / 2}\right)$ for the recycled catalyst shifted $0.17 \mathrm{eV}$ higher in terms of binding energy compared to the fresh catalyst. Because a more positive charge density on typical transition metal atoms results in higher binding energies, the Ag nanoparticles were more positive after five runs, which 


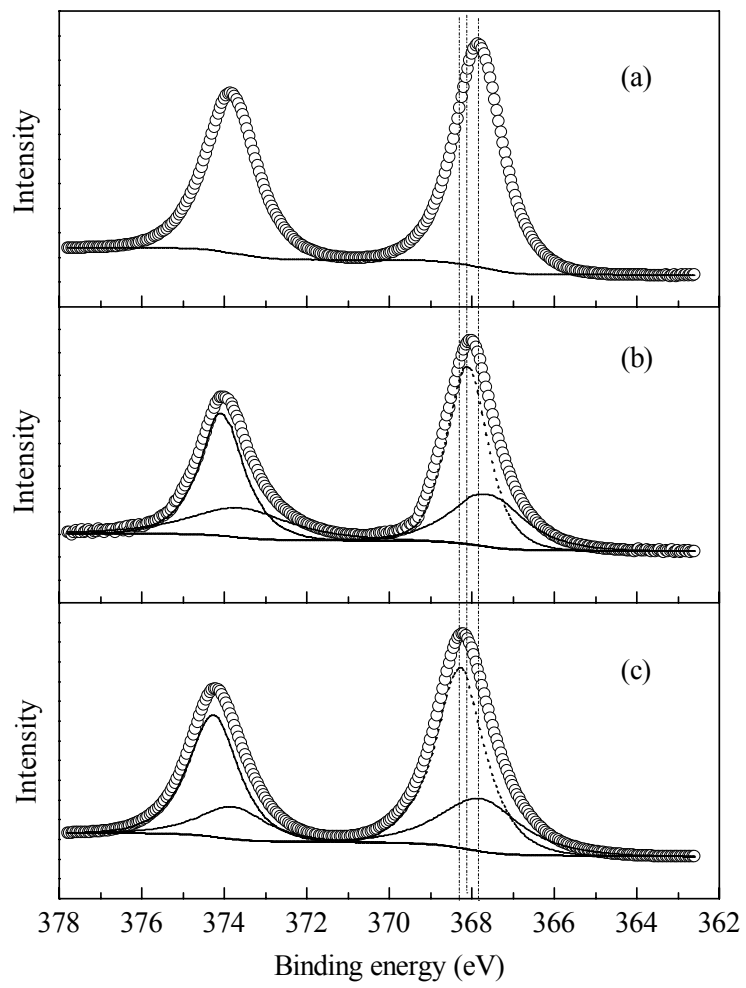

Fig. 5. Representative Ag $3 d$ XPS spectra of the nanocomposites. (a) The catalyst was not reduced by $\mathrm{NaBH}_{4}$; (b) $10 \% \mathrm{Ag} / 0.4 \% \mathrm{KOH}-$ $\gamma-\mathrm{Fe}_{2} \mathrm{O}_{3}$; (c) $10 \% \mathrm{Ag} / 0.4 \% \mathrm{KOH}-\gamma-\mathrm{Fe}_{2} \mathrm{O}_{3}$ after five runs.

might be due to the oxidant in the reaction system.

The detailed XPS parameters of all the samples are summarized in Table 1. The XPS spectra also contained a K $2 p$ signal and the $\mathrm{K} 2 p_{3 / 2}$ peak was present at a binding energy of $292 \mathrm{eV}[35,36]$. The peak intensity and binding energy of the $\mathrm{K} 2 p$ peak did not change after these reactions (Table 1).

Table 1 XPS results of the catalysts

\begin{tabular}{lccc}
\hline \multirow{2}{*}{ Catalyst } & \multicolumn{3}{c}{ Binding energy (eV) } \\
\cline { 2 - 4 } & $\mathrm{Ag} 3 d_{5 / 2}$ & $\mathrm{Fe} 2 p_{3 / 2}$ & $\mathrm{~K} 2 p_{3 / 2}$ \\
\hline $\mathrm{Ag}_{2} \mathrm{O} / 0.4 \% \mathrm{KOH}-\gamma-\mathrm{Fe}_{2} \mathrm{O}_{3}{ }^{\mathrm{a}, \mathrm{b}}$ & 367.84 & 710.43 & 292.20 \\
$\mathrm{Ag} / 0.4 \% \mathrm{KOH}-\gamma-\mathrm{Fe}_{2} \mathrm{O}_{3}{ }^{\mathrm{b}}$ & 367.60 & 710.48 & 292.15 \\
& 368.09 & & \\
$\mathrm{Ag} / 0.39 \% \mathrm{KOH}-\gamma-\mathrm{Fe}_{2} \mathrm{O}_{3}{ }^{\mathrm{b}, \mathrm{c}}$ & 367.79 & 710.46 & 292.20 \\
& 368.26 & & \\
\hline
\end{tabular}

${ }^{\mathrm{a}}$ The unreduced catalyst was used.

${ }^{\mathrm{b}}$ The potassium hydroxide content was determined by ICP-AES.

${ }^{\mathrm{c}} 10 \% \mathrm{Ag} / 0.4 \% \mathrm{KOH}-\gamma-\mathrm{Fe}_{2} \mathrm{O}_{3}$ was recycled five times.

\subsection{Catalytic activity for epoxidation with the magnetic silver catalyst}

The transformation of styrene to styrene oxide (SO) upon catalysis by the $\gamma-\mathrm{Fe}_{2} \mathrm{O}_{3}, \mathrm{KOH}-\gamma-\mathrm{Fe}_{2} \mathrm{O}_{3}, \mathrm{Ag} / \gamma-\mathrm{Fe}_{2} \mathrm{O}_{3}$, and $\mathrm{Ag} / \mathrm{KOH}-\gamma-\mathrm{Fe}_{2} \mathrm{O}_{3}$ catalysts was investigated and the results are listed in Table 2. We found that only benzaldehyde (BZ) was formed as a main by-product. The content of $\mathrm{Ag}$ in the $\mathrm{Ag} / \mathrm{KOH}-\gamma-\mathrm{Fe}_{2} \mathrm{O}_{3}$ catalyst has been optimized and we show that a catalyst loading of $10 \% \mathrm{Ag}$ gives the most active catalyst. Therefore, catalysts loaded with $10 \%$ Ag were used in the following studies.

When single $\gamma-\mathrm{Fe}_{2} \mathrm{O}_{3}$ was used as the catalyst the selectivity for $\mathrm{SO}$ and $\mathrm{BZ}$ was $47.8 \%$ and $52.2 \%$, respectively (Table 2, entry 2). The selectivity for $\mathrm{SO}$ was improved to $81.9 \%$ when using the $10 \% \mathrm{Ag} / \gamma-\mathrm{Fe}_{2} \mathrm{O}_{3}$ catalyst (Table 2, entry 4), which confirmed clearly that both $\mathrm{Ag}$ and $\gamma-\mathrm{Fe}_{2} \mathrm{O}_{3}$ components played a synergic role in the catalytic epoxidation. It has been reported previously that $\gamma-\mathrm{Fe}_{2} \mathrm{O}_{3}$ provides reactive oxygen species [37,38] and the active species may easily transfer to the surface of the proximate Ag particles in the nanocatalyst. As a consequence, this process facilitated the epoxidation of the styrene molecules adsorbed on the Ag surface. Styrene epoxidation gave a very low conversion (16.4\%) in the absence of a catalyst (Table 2, entry 1 ), which demonstrates the necessity for a catalyst in this system.

Table 2 Epoxidation of styrene with different catalysts in ethyl acetate

\begin{tabular}{|c|c|c|c|c|}
\hline \multirow{2}{*}{ Entry } & \multirow{2}{*}{ Catalyst } & \multirow{2}{*}{$\begin{array}{c}\text { Conversion } \\
(\%)\end{array}$} & \multicolumn{2}{|c|}{ Selectivity (mol\%) } \\
\hline & & & $\mathrm{SO}$ & $\mathrm{BZ}$ \\
\hline 1 & None & 16.4 & 41.8 & 58.2 \\
\hline 2 & $\gamma-\mathrm{Fe}_{2} \mathrm{O}_{3}$ & 80.7 & 47.8 & 52.2 \\
\hline $3^{\mathrm{a}}$ & $0.4 \% \mathrm{KOH}-\gamma-\mathrm{Fe}_{2} \mathrm{O}_{3}$ & 78.5 & 53.6 & 46.4 \\
\hline 4 & $10 \% \mathrm{Ag} / \gamma-\mathrm{Fe}_{2} \mathrm{O}_{3}$ & 70.0 & 81.9 & 18.1 \\
\hline $5^{\mathrm{a}}$ & $10 \% \mathrm{Ag} / 0.1 \% \mathrm{KOH}-\gamma-\mathrm{Fe}_{2} \mathrm{O}_{3}$ & 79.9 & 83.0 & 17.0 \\
\hline $6^{\mathrm{a}}$ & $10 \% \mathrm{Ag} / 0.4 \% \mathrm{KOH}-\gamma-\mathrm{Fe}_{2} \mathrm{O}_{3}$ & 89.6 & 89.7 & 10.3 \\
\hline $7^{\mathrm{a}}$ & $10 \% \mathrm{Ag} / 0.91 \% \mathrm{KOH}-\gamma-\mathrm{Fe}_{2} \mathrm{O}$ & 75.5 & 82.7 & 17.3 \\
\hline
\end{tabular}

Reaction conditions: styrene $1 \mathrm{mmol}$, catalyst $20 \mathrm{mg} \mathrm{Ag} 18.5 \mu \mathrm{mol}$, ethyl acetate $1.792 \mathrm{~g}(2 \mathrm{ml})$, TBHP $3 \mathrm{mmol}, 80{ }^{\circ} \mathrm{C}, 15 \mathrm{~h}, \mathrm{~N}_{2}$ atmosphere. Conversion and selectivity were determined by $\mathrm{GC}$ analysis. ${ }^{a}$ The contents of potassium hydroxide were determined by ICP-AES.

\subsubsection{Effect of K loading}

The effects of different $\mathrm{KOH}$ loadings on the conversion of styrene and the selectivity for $\mathrm{SO}$ were also examined (Table 2, entries 5-7). When $0.4 \% \mathrm{KOH} / \gamma-\mathrm{Fe}_{2} \mathrm{O}_{3}$ was used as the catalyst, the selectivities for $\mathrm{SO}$ and $\mathrm{BZ}$ were $53.6 \%$ and $46.4 \%$, respectively (Table 2 , entry 3 ). Obviously, the $\gamma-\mathrm{Fe}_{2} \mathrm{O}_{3}$ modified by a solid base $\mathrm{KOH}$ improved the selectivity for SO. Moreover, it can be seen that with an increase in the amount of $\mathrm{KOH}$ loading in the supported-silver catalyst both the conversion of styrene and the selectivity for $\mathrm{SO}$ increased correspondingly and a maximum was found for $0.4 \% \mathrm{KOH}$ (Table 2, entries 5 and 6). However, when the supported amounts of $\mathrm{KOH}$ exceeded $0.4 \%$, the conversion and selectivity dropped to $75.5 \%$ and $82.7 \%$ (Table 2 , 
entry 7), respectively.

\subsubsection{Effect of solvents}

As shown in Table 3, the epoxidation of styrene in different media was investigated. It was clear that the properties of the solvents greatly affected the conversion and selectivity. Benzoic acid (BA) was the main product obtained under solvent-free conditions after a $15 \mathrm{~h}$ reaction (Table 3 , entry 2). The selectivity for $\mathrm{SO}, \mathrm{BZ}$, and $\mathrm{BA}$ is almost the same $(36.4 \%, 30.9 \%$, and $32.7 \%$, respectively) with a reaction time of $7 \mathrm{~h}$ (Table 3, entry 1). This implied that SO and $\mathrm{BZ}$ can be further oxidized to BA possibly because of the high local concentration of SO, BZ, and TBHP around the catalyst under solvent-free conditions. When the reaction was performed in an aqueous medium, with an increase in the reaction time the selectivity for SO decreased while that for the aldehyde increased (not shown). After a $15 \mathrm{~h}$ reaction time, BZ was the main product with a moderate conversion (Table 3, entry 3). The change in selectivity for BA and phenylethylene glycol was found to be quite small. The observed variation in product selectivity suggests that $\mathrm{SO}$ undergoes $\mathrm{C}-\mathrm{C}$ bond breakage to produce $\mathrm{BZ}$ as the main product in the water medium. Solvents like ethanol (SCRC, AR grade), ethyl acetate, and acetonitrile (Shanghai Ling Feng Chemical Reagent Co., Ltd., AR grade) (Table 3, entries 4-6) are more favorable for the formation of SO. The conversion of styrene in ethyl acetate and acetonitrile was higher and reached $89.6 \%$ and $90.5 \%$, respectively. Because ethyl acetate is a more environmentally benign solvent it was used as a reaction medium in the following catalytic reactions.

Table 3 Epoxidation of styrene with the $10 \% \mathrm{Ag} / 0.4 \% \mathrm{KOH}-\gamma-\mathrm{Fe}_{2} \mathrm{O}_{3}$ catalyst in different solvents

\begin{tabular}{cccrccc}
\hline \multirow{2}{*}{ Entry } & \multirow{2}{*}{ Solvent } & Conversion & \multicolumn{4}{c}{ Selectivity (mol\%) } \\
\cline { 4 - 7 } & & $(\%)$ & \multicolumn{1}{c}{ SO } & BZ & BA & Enol \\
\hline $1^{\text {a }}$ & none & 48.6 & 36.4 & 30.9 & 32.7 & 0 \\
2 & none & 74.1 & 4.8 & 10.3 & 84.9 & 0 \\
3 & water & 47.8 & 12.1 & 72.9 & 12.5 & 2.4 \\
4 & ethanol & 37.9 & 85.6 & 14.4 & 0 & 0 \\
5 & ethyl & & & & 0 & 0 \\
& acetate & 89.6 & 89.7 & 10.3 & 0 & \\
6 & acetonitrile & 90.5 & 89.6 & 10.4 & 0 & 0 \\
\hline
\end{tabular}

Reaction conditions: styrene $1 \mathrm{mmol}$, catalyst $20 \mathrm{mg}$ (Ag $18.5 \mu \mathrm{mol}$ ), solvent $2 \mathrm{ml}$, TBHP $3 \mathrm{mmol}, 80^{\circ} \mathrm{C}, 15 \mathrm{~h}\left({ }^{\mathrm{a}} 7 \mathrm{~h}\right), \mathrm{N}_{2}$ atmosphere. Conversion and selectivity were determined by $\mathrm{GC}$ analysis.

\subsubsection{Reaction kinetics and catalyst recycling}

The catalytic performance of the epoxidation of styrene versus reaction time was studied and this is shown in Fig. 6. The conversion of styrene increased continuously with time

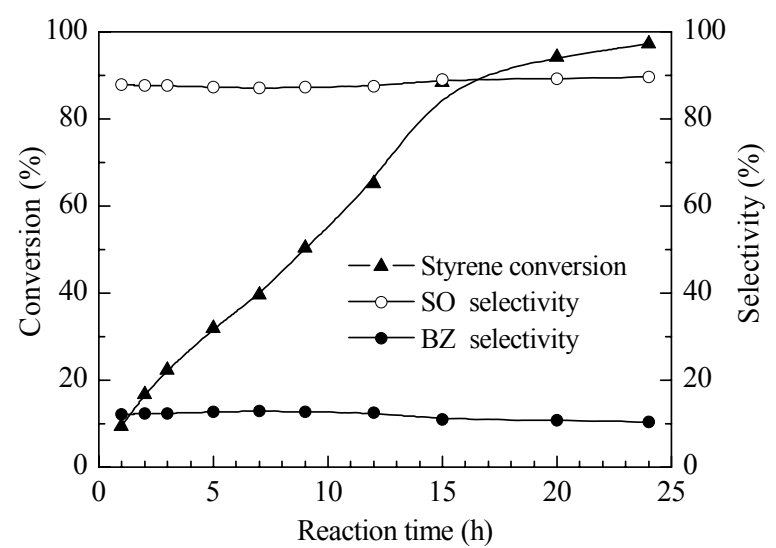

Fig. 6. Catalytic performance of the $10 \% \mathrm{Ag} / 0.4 \% \mathrm{KOH}-\gamma-\mathrm{Fe}_{2} \mathrm{O}_{3}$ catalyst as a function of reaction time. Reaction conditions: styrene 1 mmol, catalyst $20 \mathrm{mg}$ (Ag $18.5 \mu \mathrm{mol})$, ethyl acetate $1.792 \mathrm{~g}(2 \mathrm{ml})$, TBHP 3 mmol, $80{ }^{\circ} \mathrm{C}, \mathrm{N}_{2}$ atmosphere.

and was close to full conversion after $24 \mathrm{~h}$. The yield of styrene epoxide was comparable with many of the heterogeneous catalytic systems reported earlier, even in other organic solvents $[39,40]$. Interestingly, both the selectivity for SO (ca. 89\%) and BZ (ca. 10\%) were low and constant during the whole process. This data shows that the SO and $\mathrm{BZ}$ were formed simultaneously in the reaction. The selectivity for $\mathrm{SO}$ was quite high and the formation of $\mathrm{BZ}$ or $\mathrm{BA}$ was suppressed considerably in ethyl acetate compared with that in aqueous medium or without the use of a solvent. Our proposed reaction mechanism is shown in Scheme 2.

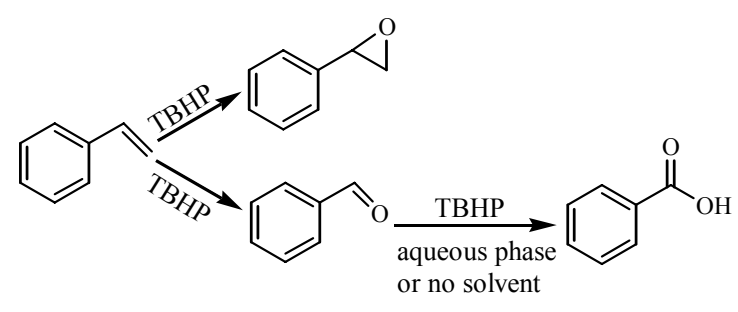

Scheme 2. Reaction scheme for the epoxidation of styrene.

Recycling experiments were also undertaken for the epoxidation of styrene using the $\mathrm{Ag} / \mathrm{KOH}-\gamma-\mathrm{Fe}_{2} \mathrm{O}_{3}$ catalyst (Fig. 7). After the first reaction, the catalyst was recovered easily using a permanent magnet and the products were simply collected by decantation. The recovered catalyst was then washed with ethyl acetate $(1 \mathrm{ml} \times 3)$ and dried under vacuum. The catalyst was reused in successive epoxidations by the addition of fresh solvent, TBHP, and substrate. The catalytic system gave $89.6 \%$ conversion for the second run and $80.1 \%$ conversion for the fifth run. Because the charge density, the overall shape and the size distribution of the catalytically active silver nanoparticles did not change significantly after consecutive runs as discussed above a gradual decrease in the conversion of styrene occurred. This was possibly because of the dissolution of silver or potassium 


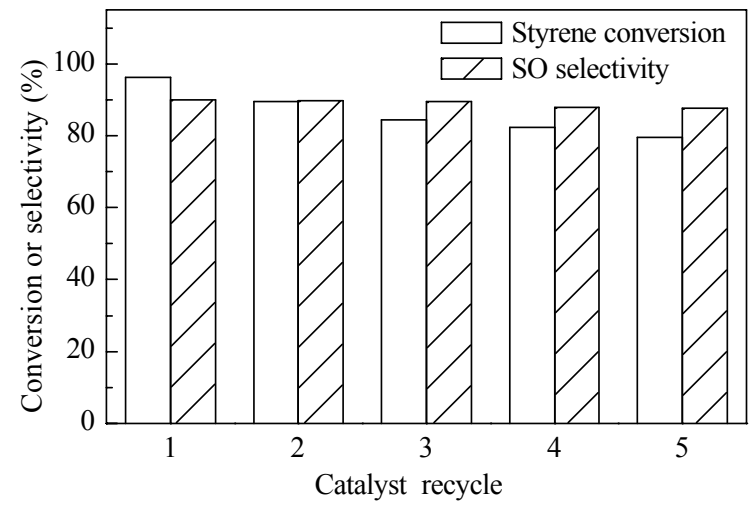

Fig. 7. Reuse of the $10 \% \mathrm{Ag} / 0.4 \% \mathrm{KOH}-\gamma-\mathrm{Fe}_{2} \mathrm{O}_{3}$ catalyst for the epoxidation of styrene. Reaction conditions: styrene $1 \mathrm{mmol}$, catalyst $20 \mathrm{mg}$ (Ag $18.5 \mu \mathrm{mol})$, ethyl acetate $1.792 \mathrm{~g} \mathrm{(2} \mathrm{ml),} \mathrm{TBHP} 3 \mathrm{mmol}, 80$ ${ }^{\circ} \mathrm{C}, 24 \mathrm{~h}, \mathrm{~N}_{2}$ atmosphere.

leaching into the reaction mixture, especially in the liquid phase oxidation reactions. To address this possibility, the isolated products obtained after magnetic separation were analyzed by ICP-AES. We found that the Ag concentration in the reaction effluent was only $0.3 \times 10^{-6}$ and the content of $\mathrm{KOH}$ in the reused $\mathrm{Ag} / \mathrm{KOH}-\gamma-\mathrm{Fe}_{2} \mathrm{O}_{3}$ catalyst remained unchanged $(0.39 \%)$. This indicates that the leaching of $\mathrm{Ag}$ or $\mathrm{K}$ during the reaction was negligible. Based on the analysis above, the strong adsorption of the reaction products onto the surface of the catalyst could be the reason for the slow deactivation in the catalytic runs. This is also shown by the C-H stretching bands (2961.2 and $2926.7 \mathrm{~cm}^{-1}$ ) present in the IR spectra of the reused catalyst by comparison with the fresh catalyst. Because of the high affinity of $\mathrm{Ag}$ and $\mathrm{KOH}$ for the magnetic support, a highly efficient magnetic separation can be achieved for this catalytic system.

\subsubsection{Epoxidation reaction of different substrates}

In the next step, the generality of the oxidative reaction was investigated by varying the alkene substrates and comparing their conversions and product selectivities as listed in Table 4 . The $10 \% \mathrm{Ag} / 0.4 \% \mathrm{KOH}-\gamma-\mathrm{Fe}_{2} \mathrm{O}_{3}$ catalyst showed much higher activity for styrene than the cycloolefins and

Table 4 Epoxidation of various substrates with the $10 \% \mathrm{Ag} /$ $0.4 \% \mathrm{KOH}-\gamma-\mathrm{Fe}_{2} \mathrm{O}_{3}$ catalyst in ethyl acetate

\begin{tabular}{cccccc}
\hline \multirow{2}{*}{ Entry } & \multirow{2}{*}{ Substrate } & Conversion & \multicolumn{3}{c}{ Selectivity (mol\%) } \\
\cline { 4 - 6 } & & $(\%)$ & Epoxides & Aldehyde & Enols \\
\hline 1 & styrene & 89.6 & 89.7 & 10.3 & - \\
2 & cyclohexene & 26.6 & 30.1 & - & 69.9 \\
3 & cyclooctene & 28.5 & 91.4 & - & 8.6 \\
4 & 1-octene & 14.2 & 93.8 & - & 6.2 \\
\hline
\end{tabular}

Reaction conditions: substrate $1 \mathrm{mmol}$, catalyst $20 \mathrm{mg} \mathrm{(Ag} 18.5 \mu \mathrm{mol})$, ethyl acetate $1.792 \mathrm{~g}(2 \mathrm{ml})$, TBHP $3 \mathrm{mmol}, 80^{\circ} \mathrm{C}, 15 \mathrm{~h}, \mathrm{~N}_{2}$ atmosphere. Conversion and selectivity were determined by $\mathrm{GC}$ analysis. the linear alkene. The styrene, cyclooctene (Alfa Aesar, AR grade), and 1-octene (Alfa Aesar, AR grade) were converted into corresponding epoxides with excellent selectivity (Table 4 , entries 1,3 , and 4) but the oxidation of cyclohexene (SCRC, AR grade) resulted in the production of enols (Table 4 , entry 2 ).

\section{Conclusions}

A supported silver catalyst was successfully prepared by the reduction of silver salts and they were supported on the magnetically recoverable $\gamma-\mathrm{Fe}_{2} \mathrm{O}_{3}$. The magnetically recyclable catalyst system was highly efficient in catalyzing the epoxidation of styrene with ethyl acetate as the reaction medium. The reduced metallic Ag component and the supported-base promoter played important roles in improving activity and selectivity during styrene epoxidation. Obviously, this catalyst system is green, simple, easily separable, and recyclable.

\section{Acknowledgments}

The authors would like to express their thanks to Prof. Walter Leitner for the helpful suggestion and Dr. Nils Theyssen for assistance.

\section{References}

1 Zhang D H, Li G D, Li J X, Chen J S. Chem Commun, 2008: 3414

2 Tyagi B, Shaik B, Bajaj H C. Catal Commun, 2009, 11: 114

3 Garade A C, Bharadwaj M, Bhagwat S V, Athawale A A, Rode C V. Catal Commun, 2009, 10: 485

4 Dioumaev V K, Bullock R M. Nature, 2003, 424: 530

5 Liu J H, Wang F, Gu Z G, Xu X L. Catal Commun, 2009, 10: 868

6 Chimentão R J, Kirm I, Medina F, Rodríguez X, Cesteros Y, Salagre P, Sueiras J E, Fierro J L G. Appl Surf Sci, 2005, 252: 793

7 Liu J H, Wang F, Xu T, Gu Z G. Catal Lett, 2010, 134: 51

8 Liu Y M, Tsunoyama H, Akita T, Tsukuda T. Chem Commun, 2010, 46: 550

9 Choudhary V R, Jha R, Chaudhari N K, Jana P. Catal Commun, 2007, 8: 1556

10 王广健, 刘正旺, 刘义武, 刘广卿, 徐明霞, 王 否. 催化学 报(Wang G J, Liu Zh W, Liu Y W, Liu G Q, Xu M X, Wang L. Chin J Catal), 2008, 29: 1159

11 Jiang J, Li R, Wang H L, Zheng Y F, Chen H N, Ma J T. Catal Lett, 2008, 120: 221

12 Chou K S, Lee S J. Colloid Surf A, 2009, 336: 23

13 Rane K S, Verenkar V M S, Pednekar R M, Sawant P Y. J Mater Sci Mater Electron, 1999, 10: 121

14 Basak S, Rane K S, Biswas P. Chem Mater, 2008, 20: 4906 
15 Shi F, Tse M K, Pohl M M, Radnik J, Brückner A, Zhang S M, Beller M. J Mol Catal A, 2008, 292: 28

16 Zhang Y, Li Z, Sun W, Xia C G. Catal Commun, 2008, 10: 237

17 Zhang Y, Xia C G. Appl Catal A, 2009, 366: 141

18 Liu H Q, Liang M H, Xiao C, Zheng N, Feng X H, Liu Y, Xie J L, Wang Y. J Mol Catal A, 2009, 308: 79

19 Oliveira R L, Kiyohara P K, Rossi L M. Green Chem, 2010, 12: 144

20 Qi B, Lu X H, Zhou D, Xia Q H, Tang Z R, Fang S Y, Pang T, Dong Y L. J Mol Catal A, 2010, 322: 73

21 Wilson K, Hardacre C, Lee A F, Montero J M, Shellard L. Green Chem, 2008, 10: 654

22 李渊, 赵新强, 王延吉. 催化学报 (Li Y, Zhao X Q, Wang Y J. Chin J Catal), 2004, 25: 633

23 Macala G S, Matson T D, Johnson C L, Lewis R S, Iretskii A V, Ford P C. ChemSusChem, 2009, 2: 215

24 Calvino-Casilda V, Martin-Aranda R M, Lopez-Peinado A J, Sobczak I, Ziolek M. Catal Today, 2009, 142: 278

25 Sharma S K, Parikh P A, Jasra R V. J Mol Catal A, 2010, 317: 27

26 Teng X W, Black D, Watkins N J, Gao Y L, Yang H. Nano Lett, 2003, 3: 261

27 Liu X M, Li Y S. Mater Sci Eng C, 2009, 29: 1128

28 Pereira C, Pereira A M, Quaresma P, Tavares P B, Pereira E,
Araújo J P, Freire C. Dalton Trans, 2010, 39: 2842

29 Lutzenkirchen-Hecht D, Strehblow H H. Surf Interface Anal, 2009, 41: 820

30 You X F, Chen F, Zhang J L, Anpo M. Catal Lett, 2005, 102: 247

31 Sangpour P, Babapour A, Akhavana O, Moshfegh A Z. Surf Interface Anal, 2009, 41: 157

32 Mackova A, Malinsky P, Bocan J, Svorcik V, Pavlik J, Stryhal Z, Sajdl P. Phys Stat Sol C, 2008, 5: 964

33 Zhang D H, Li H B, Li G D, Chen J S. Dalton Trans, 2009, 47: 10527

34 Schnippering M, Carrara M, Foelske A, Kötz R, Fermín D J. Phys Chem Chem Phys, 2007, 9: 725

35 Miyakoshi A, Ueno A, Ichikawa M. Appl Catal A, 2001, 219: 249

36 Hope G A, Woods R, Buckley A N, White J M, McLean J. Inorg Chim Acta, 2010, 363: 935

37 Schubert M M, Hackenberg S, Van Veen A C, Muhler M, Plzak V, Behm R J. J Catal, 2001, 197: 113

38 Liu H C, Kozlov A I, Kozlova A P, Shido T, Iwasawa Y. Phys Chem Chem Phys, 1999, 1: 2851

39 Yang Y, Guan J Q, Qiu P P, Kan Q B. Transition Met Chem, 2010, 35: 263

40 Lu X N, Yuan Y Z. Appl Catal A, 2009, 365: 180 